Original Research Article

\title{
Quality, quantity and recovery of DNA content from routine blood samples and genotyping success rate: comparison between phenol chloroform method (PCM) with a new kit-based DNA extraction method (KBM)
}

\author{
Gopisankar M. G.*, Surendiran A., Hemachandren M., Rajan S.
}

Department of Pharmacology, JIPMER, Puducherry, India

Received: 09 August 2018

Revised: 20 August 2018

Accepted: 24 August 2018

*Correspondence to:

Dr. Gopisankar M. G.,

Email: spaarkingo@gmail.com

Copyright: () the author(s), publisher and licensee Medip Academy. This is an openaccess article distributed under the terms of the Creative Commons Attribution NonCommercial License, which permits unrestricted noncommercial use, distribution, and reproduction in any medium, provided the original work is properly cited.

\begin{abstract}
Background: DNA extraction has become a baseline method for molecular biology studies. There are a variety of methods available for this purpose. Newer kit-based methods (KBM) are easy and less time consuming than traditional chemical methods of extraction like phenol chloroform method (PCM). Though estimates of quality from different methods are available in labels, this study compared the practical outcomes regarding quantity, quality, DNA recovery rate and assessed the outcomes at two different time points.

Methods: This study was done as a secondary analysis from an ongoing project. The quantity and quality of DNA isolated from the same group of 100 deidentified blood samples by PCM and KBM were analysed using Multi analyzer and repeated after a period of 3 months. Genotyping of the samples were done by RT-PCR. The quantity, quality and amplification proportion were compared between two groups to reach the inference.

Results: The median (range) concentration of DNA by PCM was 543.27 (960.59) $\mu \mathrm{g} / \mathrm{ml}$ and that of $\mathrm{KBM}$ was $32.115(36.73) \mu \mathrm{g} / \mathrm{ml}$. The quality of DNA as measured by absorbance at $260 / 280 \mathrm{~nm}$ was 1.84 in PCM and 1.81 in KBM ( $\mathrm{p}>0.05$ ). Genotyping success rate was $78 \%$ in PCM and $98 \%$ in $\mathrm{KBM}$ ( $\mathrm{p}=$ 0.002). The DNA recovery rate was $96 \%$ in PCM and $80 \%$ in KBM (p=0.014).

Conclusions: The median concentration of DNA obtained from PCM was more compared to KBM. The quality of DNA was comparable in both the groups. The genotyping success rate was more in KBM group. The DNA recovery rate at 3 months was more in PCM group.
\end{abstract}

Keywords: Genotype detection, Kit based DNA method, Phenol chloroform method

\section{INTRODUCTION}

Isolation of DNA is one of the most commonly done procedures in molecular biology and biochemistry. High quantity of pure and intact DNA concentration is required for newer techniques like next generation sequencing and micro-array technologies. There are different methods of DNA extraction depending on the source from which it has to be isolated, availability of time, and number of samples to be analysed and cost effectiveness. Fresh or frozen blood (anti coagulated or clotted) is the most common biological fluid used for DNA isolation. Other samples include tissues, urine, stool, plasma, serum, amniotic fluid, synovial fluid and CSF. Older chemical methods of isolation include phenol chloroform method (PCM), salting out method, boiling method etc. The newer ones include improved silica method, kit based methods (KBM) and automated DNA extraction system. The traditional method of isolation is by PCM which works on the principle of liquid-liquid extraction. This method was 
introduced in early 1950 s and is still the most commonly used procedure at least in the academic research. Newer kit based methods has reduced the time and man power needed for DNA extraction and has shown to improve the quality of DNA due to more perfect separation of RNA and other protein impurities.

DNA requirement varies according to the downstream process for which it was done. Usually for whole genome genotyping around $6 \mu \mathrm{g}$ is needed and for microarray methods need $3 \mu \mathrm{g}$ of DNA quantity. ${ }^{1,2}$ The minimum concentration required for NGS and microarray method is $50 \mu \mathrm{g} / \mathrm{mL}$. Studies have been done to compare many of the available kit based methods with the chemical method of separation but limited to absolute outcomes of concentration comparison between methods obtained at the initial time..$^{3-6}$

The main rationale of this study was to assess and compare the DNA extraction efficacy of PCM and kit based method and evaluation at two different time points. This study gives an estimate of the quality, quantity, genotype success rate and DNA recovery rate from blood samples from two methods (PCM vs. KBM) and thus gives a value for the expected loss during sample analysis. The researchers can use this to foresee the loss and modify their sample size and study design accordingly.

\section{METHODS}

\section{Sample collection}

Form an on-going clinical research involving blood sample collection, 100 venous blood samples, each of $5 \mathrm{ml}$ collected by venepuncture were chosen. Peripheral blood samples were collected in vacutainer with $\mathrm{K}_{2}$ EDTA (BD 368589 , $10.8 \mathrm{mg}$ in $10 \mathrm{ml}$ tube, Becton Dickinson $\AA$ diagnostics). Samples were properly mixed by inversion and transported to laboratory in isothermic boxes to prevent quality loss of samples. The samples were randomly divided into two groups of 50 each. Random numbers were generated using Graph Pad Prism v.7. Proper de-identification of the samples was done before the start of the study. Phenol chloroform method of DNA extraction was done in 50 whole blood samples after centrifugation at $2500 \mathrm{rpm}$ for 10 minutes. Kit based method was done in 50 samples using buffy coat for higher yield. The used kit was QIAamp® DNA mini blood mini (Qiagen; Hilden, Germany). ${ }^{7}$ Buffy coat was prepared by centrifugation at $3000 \mathrm{~g}$ for $10 \mathrm{~min}$ in Sorvall ${ }^{\circledR}$ Legend XT centrifuge (Massachusetts, USA) at $25^{\circ} \mathrm{C}$ to separate whole blood to plasma, platelets and WBC. Plasma was discarded and the buffy coat was separated out. The study was approved by institute ethics committee, JIPMER, Puducherry, India.

\section{DNA extraction methods}

A commercially available kit-based method (Qiagen; Hilden, Germany) was chosen which used spin column method and silica plate technology. The KBM was done by following manufacturer's instructions. From $5 \mathrm{~mL}$ blood buffy coat was extracted and re-suspended in $200 \mu 1$ of PBS (physiological buffer solution). Qiagen Proteinase $\mathrm{K}, 20 \mu \mathrm{l}$ is added to digest the proteins. Samples are then incubated at $56^{\circ} \mathrm{C}$ in hot water bath for 10 minutes. $200 \mu \mathrm{l}$ of $100 \%$ ethanol is added and mixed by pulse-vortexing for 15 seconds. The mixture is transferred to spin column and centrifuged at $6000 \mathrm{~g}$ for 1 minute. Wash buffer which contains guanidine hydrochloride is added and again centrifuged. Guanidine hydrochloride acts as the chaotropic agent. Chaotropic agent disrupts the 3D structure of proteins and aids in protein denaturation. In the final step, DNA bound to silica is eluted using elution buffer which contains TRIS-EDTA in Millipore water and incubated at $4^{0} \mathrm{C}$ for one day.

PCM is a standard method of DNA extraction using proteinase $\mathrm{K}^{8}$ The chemicals used were of HPLC grade. RBC lysis solution was prepared by ammonium chloride $(8.2 \mathrm{~g})$, sodium bicarbonate $(0.84 \mathrm{~g})$ and disodium EDTA $(0.7 \mathrm{~g})$ in $100 \mathrm{ml}$ of Millipore water. Disodium EDTA $(2 \mathrm{mM})$ and $5 \% \mathrm{NaOH}$ were used to prepare WBC lysis solution. Other reagents used were Sodium dodecyl sulphate $(10 \%)$, saturated $\mathrm{NaCl}(10 \%)$, chloroformoctanol (24:1) and equilibrated phenol. The buffers used were TRIS-EDTA (pH 7.4) and TRIS (pH 8.0).

\section{Evaluation of DNA extraction}

\section{Spectrophotometer measurements}

Quantification of the extracted DNA was done using multianalyzer (Infinite M200). The sample was diluted in milliQ water and added into 96 quartz well plate. It works on the principle of Beer-lambert's law by spectrophotometer; at a particular path length $(0.26 \mathrm{~mm})$, the absorbance of the solution at $260 \mathrm{~nm}$ will be proportional to the concentration of DNA in the sample. ${ }^{9}$ The absorbance at $280 \mathrm{~nm}$ was measured to assess protein impurities as aromatic amino acids absorb UV (Ultra violet) at this wavelength. The temperature was adjusted at $31.3^{\circ} \mathrm{C}$ for 260 and $31.2^{\circ} \mathrm{C}$ for $280 \mathrm{~nm}$, number of flashes were 25 , settle time was $20 \mathrm{~ms}$. Measurement of band width was $5 \mathrm{~nm}$. The initial results are measured as optical density. An equation was loaded in the multianalyzer to find out the corresponding DNA concentration (equation 1). The software used was Magellan version 6.5.

Input data, $\mathrm{x}=\mathrm{OD} 260, \mathrm{f}(\mathrm{x})=\left({ }^{\prime} 260 ’\right.$ ! $\times$ ‘260’! BL1)/0.26*5000..(1)

BL1 corresponds to blank correction, $\mathrm{f}(\mathrm{x})$ corresponds to function code in the programme, $\mathrm{K}$ or the absorbance constant is 0.02 and dilution factor is 100 , i.e. $1 \mu l$ of the sample in $99 \mu \mathrm{l}$ of milliQ water. $\mathrm{k}$ value is obtained from the standard calculation of absorbance 1 corresponds to $50 \mu \mathrm{g} / \mathrm{ml}$ of double standard DNA in $1 \mathrm{~cm}$ path length of the cuvette. The quality of the DNA was assessed by calculating the $\mathrm{OD}_{260} / \mathrm{OD}_{280}$ ratio. 


\section{Real-time PCR}

The obtained DNA samples were genotyped for $A B C B 1$ $2677 G>T$ single nucleotide polymorphism in quantitative reverse transcriptase PCR (qRT-PCR) from Applied Biosystems (AB 7300) and using sequence detection software, version 1.4. $A B C B 12677 G>T$ is a single nucleotide polymorphism in $\mathrm{ABCB} 1$ gene at $2677^{\text {th }}$ position. ABCB1 $2677 \mathrm{G}>\mathrm{T}$ codes for a P-glycoprotein which is an efflux protein and pumps out unwanted chemicals from the cells and thus involved in handling xenobiotic removal. We selected this genotype because the allele frequency for this gene was high in our population. The genotyping success rate defined as total number of amplifications obtained out of total samples in two groups. The quantification and quality assessment were repeated after three months after storing the DNA samples (100 samples) at similar temperature of $-80^{\circ} \mathrm{C}$ in deep freezer. DNA recovery rate was calculated based on the concentration obtained after three months of storing and comparing with the baseline values in both the groups.). It was measured by finding the proportion of stored samples with DNA by quantitating it at $260 \mathrm{~nm}$.

\section{Statistical analysis}

Concentration of DNA samples in each group were represented as median and range. The comparison of the baseline concentration and OD ratio was done using Mann-whiney U test. Chi square test was done to compare the genotyping success rate between PCM and KBM. Level of significance was kept at 0.05 . Statistical analysis was done using SPSS v.16.

\section{RESULTS}

The initial analysis was done soon after bringing the blood samples from the outpatient and inpatient units under isothermic condition. The median (range) concentration of DNA obtained by PCM was 543.27 (960.59) $\mu \mathrm{g} / \mathrm{mL}$ and that of KBM was $32.115(36.73) \mu \mathrm{g} / \mathrm{mL}$ which showed a significant difference $(\mathrm{p}<0.01)$. This result has not considered the amount of blood taken for extraction. The quality of DNA was measured on the third day as PCM is a two-day process and KBM is a one-day method. The optical density ratio at $260 / 280 \mathrm{~nm}$ was 1.82 in PCM and 1.81 in KBM which didn't show any significant difference. The expected range for good quality DNA lies between 1.7 to 1.9. Real time-PCR analysis targeting the Genotype ABCB $12677 \mathrm{G}>\mathrm{T}$ was done in the samples. In PCM $78 \%$ (39) of the samples showed genotype amplification and in KBM 98\% (49) of the samples showed amplification which showed statistically significant difference $(p=0.004)$. No amplification was detected in non-template controls. Samples which didn't show any amplification were discarded by following strict GLP. The samples were stored in deep freezer at $-70^{\circ} \mathrm{C}$ for three months. At 3 months, the same process of quantification was repeated. The concentration of DNA in PCM group was 537.29 (2450.7) and in KBM was 31.03 (60.76). RT-PCR was run again in all the samples to assess the amplification. In samples extracted using PCM, 96\% (37) showed good amplification and in samples extracted using KBM, $80 \%$ (39) showed amplification at the end of three months $(\mathrm{p}=0.028)$. There were more number samples without DNA amplification in KBM group than in PCM group.

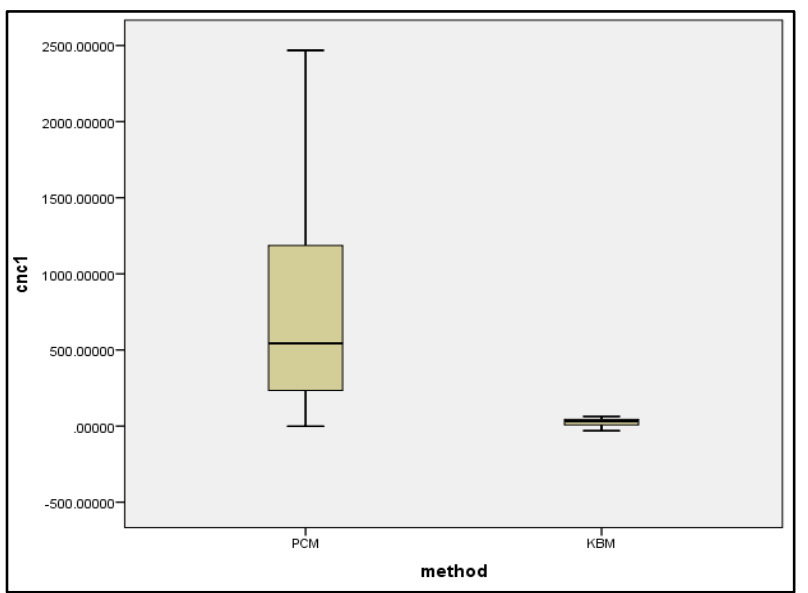

Figure 1: Comparison of concentration of quantity of DNA measured at $260 \mathrm{~nm}$ at baseline.

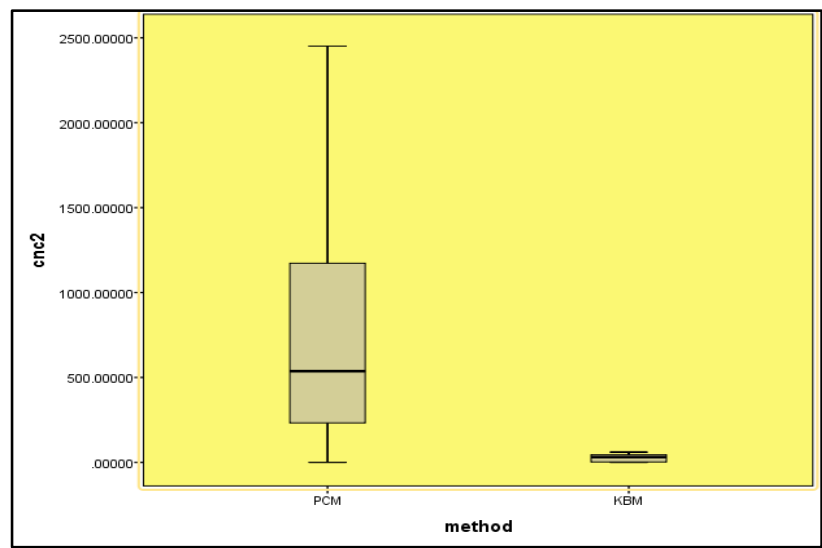

Figure 2: Comparison of concentration of quantity of DNA measured at $260 \mathrm{~nm}$ at baseline at three months.

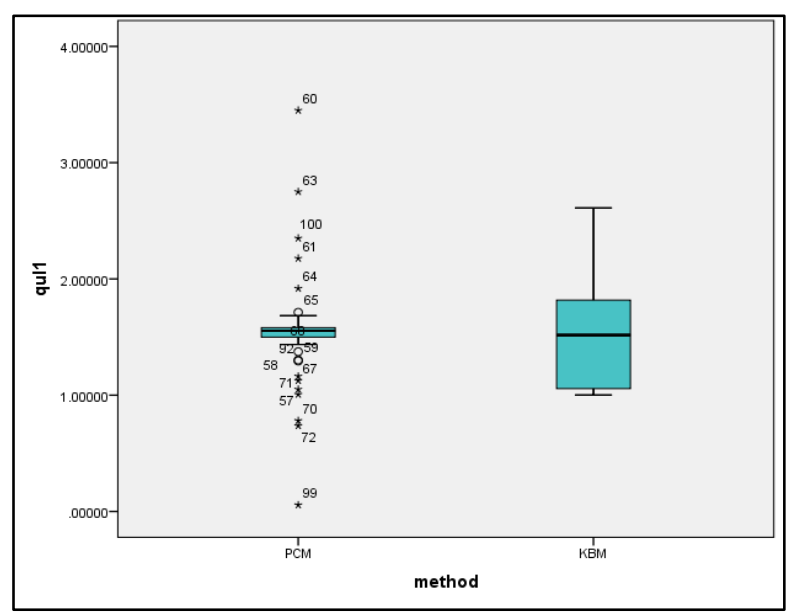

Figure 3: Comparison of quality of DNA as obtained from ratio of optical density between 260 and $280 \mathrm{~nm}$ at baseline. 


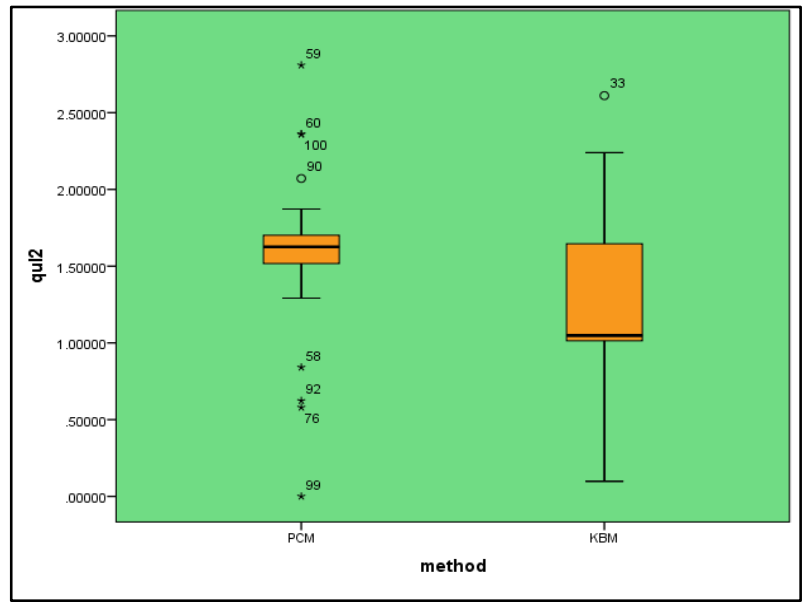

Figure 4: Comparison of quality of DNA as obtained from ratio of optical density between 260 and $280 \mathrm{~nm}$ at three months.

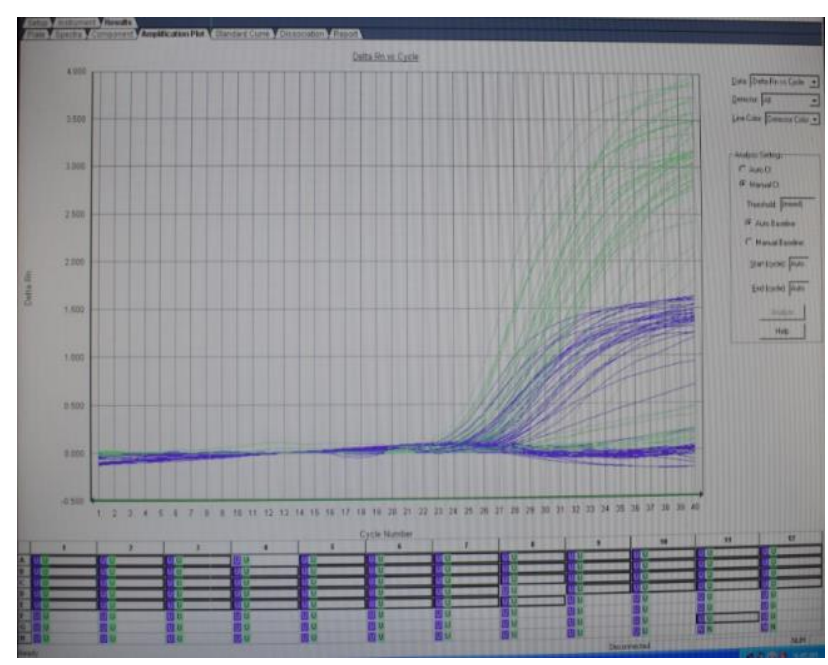

Figure 5: The amplification plots obtained by KBM for $A B C B 12677 G>T$ single nucleotide polymorphism.

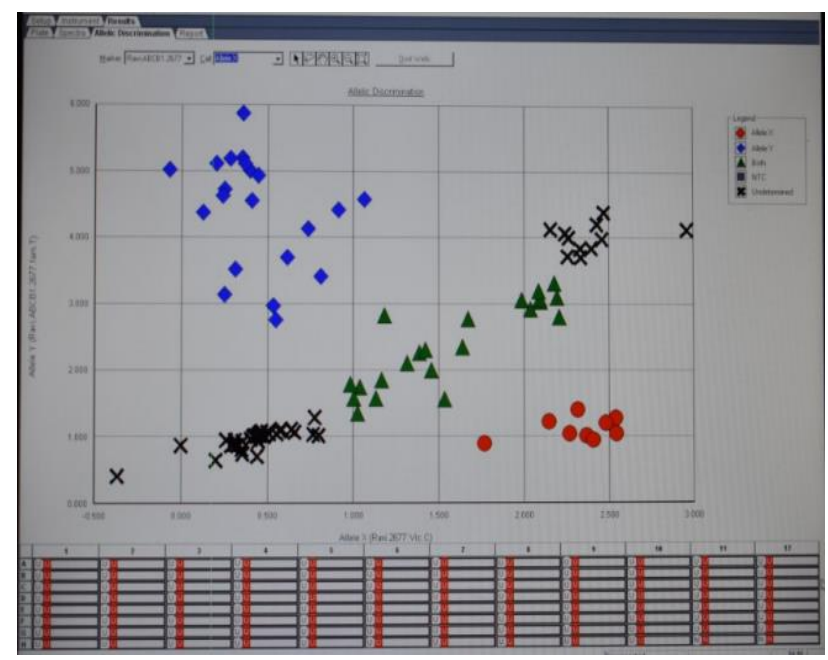

Figure 6: The allelic discrimination plots obtained by PCM for $A B C B 12677 G>T$ single nucleotide polymorphism.
Figure 1 to Figure 4 shows the comparison of two methods regarding quantity and quality and the variation of the parameters over time. Figure 5, Figure 6, Figure 7 and Figure 8 shows the amplification plots and allelic discrimination plots obtained from two methods.

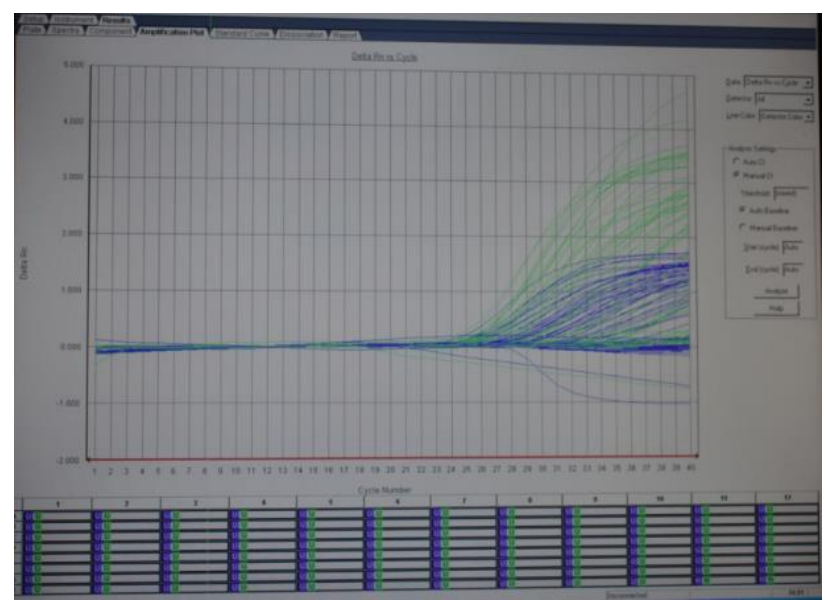

Figure 7: The amplification plots obtained by PCM for $A B C B 12677 G>T$ single nucleotide polymorphism.

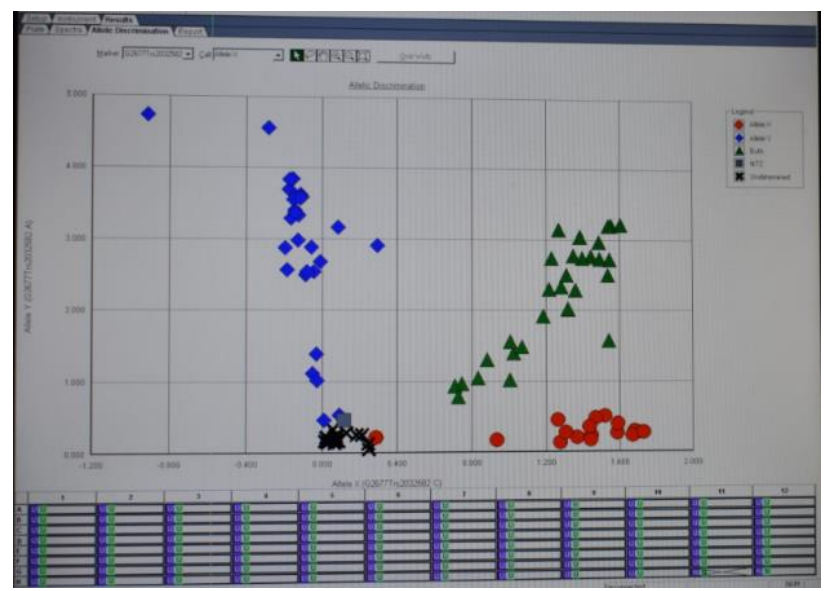

Figure 8: The allelic discrimination plots obtained by PCM for $A B C B 12677 G>T$ single nucleotide polymorphism.

\section{DISCUSSION}

This study tried to compare the DNA quality, quantity and recovery rate obtained by traditional PCM and KBM at two different time points. The median concentration obtained was more from PCM which is probably due to the higher volume of blood utilised for the procedure. The usual yield from human blood is about $100 \mu \mathrm{g}$ for every $10 \mathrm{ml}$ of blood. Different procedures are followed in the PCM, which basically includes plasma separation and cell lysis as the initial step. In liquid-liquid extraction differential solubility of individual molecules in two different non-mixing liquids is utilised. Phenol and chloroform forms the organic phase in which proteins and other hydrophobic lipids will be trapped. ${ }^{5}$ Water forms the aqueous layer in which DNA gets dissolved. Adding of 
SDS and proteinase $\mathrm{K}$ results in protein and lipid degradation. Final step is the precipitation of DNA using ethanol. The precipitated DNA can be stored in TRISEDTA (pH 8.0) buffer at $-80^{\circ} \mathrm{C}$ for long term. ${ }^{5,10}$

$\mathrm{KBM}$ is of two types, spin column method and vacuum based method. Spin column method uses centrifugal force for the separation of compounds and the latter one uses vacuum force for the extraction. The spin columns contain silica resin as the main component. It is called spin column because it uses the technique of augmenting the extraction by applying centrifugal force. Centrifugation method or spin column method includes four major steps; lysis, binding, washing and eluting. The whole blood sample is first lysed by lysis buffer to release the DNA contents from membrane bound organelles. DNA binds to this silica resin membrane during centrifugation or under vacuum conditions. ${ }^{10}$ The difference in concentration obtained from KBM and PCM is not so significant practically. It is because though we used $10 \mathrm{ml}$ of centrifuged plasma removed blood sample for quantification, the volume of blood that is contained in KBM is less whereas PCM uses the whole of the centrifuged volume. There are newer Kits available which can extract DNA from higher volume of blood samples and thus can compensate for the quantity. The quality of DNA should be ideally in the range of 1.7 to 1.9. OD ratio less than 1.7 implies protein impurities and more than 2.0 suggests RNA contamination. ${ }^{11}$

DNA binding to silica in KBM is augmented in the presence of a chaotropic agent (usually guanidine hydrochloride) as it disrupts the hydrophobic effect of nucleic acids on water molecules and thus altering its tertiary structure at a particular $\mathrm{pH} .{ }^{12}$ It also prevents proteins and other impurities from attaching to the membrane that can affect the successive reactions and running of PCR. In kit based methods there is a provision of repeated washing in case of suspected persistence of protein or lipid impurities by washing with wash buffer multiple times. DNA bound to the membrane is washed with wash buffer to remove additional impurities and an elution buffer will elute the pure nucleic acid which is collected and stored at $-30-80^{\circ} \mathrm{C}$. We noted that the range of quantity or quality (Figure 1 and 2) obtained from PCM was highly variable whereas the variation was less in KBM. Chemical processes include multiple chemicals from different manufacturers which can cause some variation in the results obtained. The precise range of values obtained from KBM is due to limited use of other chemicals (except milliQ water). Use of same grade or higher grade (e.g. HPLC grade) chemicals and also chemicals from same manufacturers may improve the precision in PCM also.

$A B C B 1$ gene mutation at $2677 G>T$ is a commonly studied polymorphism for many drug responses. The polymorphism of this gene is said to affect different classes of drugs and the therapeutic response. The genotyping success of paramount importance especially in genetic studies as it is mostly a one-time collection of blood sample and if we are not able to get the genotype in single run it can limit the scope of our study by affecting the sample size and thus the power of the study. Usually the response to many of the cancer chemotherapeutic agents are affected by genetic variation. So, the blood sample collection from morbid patients will have to be carried out for such studies and thus initial genotype success rate is so much relevant for such studies as sampling the morbid patients again is not acceptable on ethical grounds. The success rate of genotyping as shown by amplification plot or allelic discrimination demonstrated more success in KBM (98\% vs. 78\%). The chance of having a good amplification was 13 times more in $\mathrm{KBM}$ compared to PCM at $\mathrm{p}$ value of 0.004 . One of the confounding factors can be improper dilution. Since the concentration obtained from PCM is high the dilution needed to run PCR will be more. There will be errors in dilution which can cause increased DNA concentration exposure to RT-PCR. The ideal concentration to be loaded for PCR is $50 \mu \mathrm{g} / \mathrm{ml}^{13}$ Higher concentration of DNA can lead to non-specific binding of primers and thus can result in more negative results. So, proper dilution by calibrated micropipettor can avoid loss of results from PCM. ${ }^{14}$

As we study more or genetic basis of disease, more and more relevant genes regarding a disease or the action of drug will become evident. Storing of samples has become a must so as to repeat the tests for further relevant gene analysis. Adding of more relevant genes can even change the effect of previously studied gene du tot effects of linkage disequilibrium. There was personal experience of reduce recovery of DNA obtained by KBM. Thus, we studied a short-term recovery rate after 3 months of storing. The results showed more significant loss of samples in KBM group compared to other ( $96 \%$ vs. $80 \%$ ). The odds of having no loss is six times more in PCM compared to KBM. The cause of this loss is not known and has to be further investigated with other kits and kits of higher grade and volumes.

\section{CONCLUSION}

The median concentration of DNA obtained from PCM was more compared to KBM. The quality of DNA was comparable in both the groups. The genotyping success rate was more in KBM group. The DNA recovery rate at 3 months was more in PCM group. The study showed the actual outcome of molecular studies in a laboratory when followed standard procedures. This study can be used a practical way to fix the sample size in genetic studies, especially cross-sectional studies so that along with patient drop out, the laboratory loss can also be considered. The study has to be repeated for its validity in similar laboratory setups. It can repeat with use of higher grade chemical and higher volume kits.

Funding: JIPMER intra mural funds Conflict of interest: None declared

Ethical approval: The study was approved by the Institutional Ethics Committee 


\section{REFERENCES}

1. Edinburgh Genomics ARK Genomics;2013. Available at: http://www.ark-genomics.org/news/ edinburgh-genomics. Accessed 12th June 2018.

2. LGC Group. DNA extraction kits. Available at: https://www.lgcgroup.com/our-science/genomicssolutions/nucleic-acid-extraction/dna-extractionkits/\#.Wx_e4YozbIU. Accessed 12th June 2018.

3. Brandt P, Gerdts G, Boersma M, Wiltshire KH, Wichels A. Comparison of different DNA-extraction techniques to investigate the bacterial community of marine copepods. Helgoland Marine Res. 2010 Dec;64(4):331-42.

4. Javadi A, Shamaei M, Ziazi LM, Pourabdollah M, Dorudinia A, Seyedmehdi SM, et al. Qualification study of two genomic DNA extraction methods in different clinical samples. Tanaffos. 2014;13(4):41.

5. Rohland N, Hofreiter M. Comparison and optimization of ancient DNA extraction. BioTechniques. 2007;42:343-52.

6. Gaikwad AB. DNA extraction: comparison of methodologies. Scribd. Available at: https://www.scribd.com/document/290953477/DNAExtraction-Comparison-of-Methodologies.

7. QIAamp DNA Mini and Blood Mini Handbook-EN QIAGEN. Available at: https://www.qiagen.com/us/ resources/resourcedetail id=62a200d6-faf4-469bb50f-2b59cf738962andlang=en. Accessed 12th June 2018.

8. Psifidi A, Dovas CI, Banos G. A comparison of six methods for genomic DNA extraction suitable for PCR-based genotyping applications using ovine milk samples. Mol Cell Probes. 2010;24:93-8.
9. Rodger A. Concentration Determination Using BeerLambert Law. InEncyclopedia of Biophysics 2013 (pp. 360-361). Springer, Berlin, Heidelberg.

10. Cady NC, Stelick S, Batt CA. Nucleic acid purification using microfabricated silicon structures. Biosensors and Bioelectronics. 2003 Oct 30;19(1):59-66.

11. Khare P, Raj V, Chandra S, Agarwal S. Quantitative and qualitative assessment of DNA extracted from saliva for its use in forensic identification. J Forensic Dental Sci. 2014 May;6(2):81.

12. Ghadia B, Singh AK, Khatnani T, Hirpara M, Patel S, Joshi P. An improved method of DNA purification from secondary metabolites rich medicinal plants using certain chaotropic agents. Acta physiologiae plantarum. 2016 Aug 1;38(8):207.

13. Philibert RA, Zadorozhnyaya O, Beach SR, Brody $\mathrm{GH}$. A comparison of the genotyping results using DNA obtained from blood and saliva. Psychiatric genetics. 2008 Dec;18(6):275.

14. Gudiseva HV, Hansen M, Gutierrez L, Collins DW, He J, Verkuil LD, et al. Saliva DNA quality and genotyping efficiency in a predominantly elderly population. BMC medical genomics. 2016;9(1):17.

Cite this article as: Gopisankar MG, Surendiran A, Hemachandren M, Rajan S. Quality, quantity and recovery of DNA content from routine blood samples and genotyping success rate: comparison between phenol chloroform method (PCM) with a new kitbased DNA extraction method (KBM). Int J Basic Clin Pharmacol 2018;7:1863-8. 